\title{
PERAN DIMENSI-DIMENSI ENTREPRENEURIAL MARKETING DALAM MENDORONG KESUKSESAN BISNIS UMKM DI INDUSTRI EKONOMI KREATIF
}

\author{
Ari Setiyaningrum* \\ Universitas Katolik Indonesia Atma Jaya, Indonesia \\ Yussi Ramawati \\ Universitas Katolik Indonesia Atma Jaya, Indonesia
}

\begin{abstract}
This study aims to analyze the influence of entrepreneurial marketing dimensions, including proactiveness, opportunity-focused, risk-taking orientation, innovation-oriented, customer intensity, resource leveraging, and value creation of Small and Medium Enterprises (SME's) business success in the creative economy industry. The study also examined the moderating role of company age on the entrepreneurial marketing dimension's influence on SME's business success. The study used survey methods by distributing questionnaires to 265 SME business owners in North Kalimantan. The sampling method uses nonprobability sampling with a convenience sampling technique. Data were analyzed using multiple linear regression analyses and moderated tests using the macro process of SPSS Hayes. The results of this study indicated that in the context of SMEs in the creative industry, customer intensity and value creation play a critical role in business success. Meanwhile, proactiveness, opportunity-focused, risk-taking orientation, innovation-oriented, and resource leveraging found no impact on SMEs' business success. The research also proves that the company's age moderated the impact of customer intensity on SME's success but does not moderate the influence of value creation to SME's business success.
\end{abstract}

JEL : L26, M13.

Keywords : entrepreneurial marketing, business success, small and medium entreprises, company age, creative economy industry.

\begin{abstract}
ABSTRAK
Tujuan penelitian ini adalah menganalisis pengaruh dimensi-dimensi entrepreneurial marketing yang mencakup proactiveness, opportunity-focused, risk-taking orientation, innovation-oriented, customer intensity, resource leveraging, dan value creation terhadap kesuksesan bisnis UMKM di industri ekonomi kreatif. Penelitian ini juga menguji peran moderasi usia perusahaan pada pengaruh dimensi-dimensi entrepreneurial marketing terhadap kesuksesan bisnis UMKM. Penelitian menggunakan metode survei dengan mendistribusikan kuesioner kepada 265 pemilik bisnis UMKM di Kalimantan Utara. Metode pengambilan sampel menggunakan nonprobability sampling dengan teknik convenience sampling. Data dianalisis menggunakan analisis regresi linier berganda dan analisis uji moderasi menggunakan macro process SPSS Hayes. Hasil penelitian ini menemukan bahwa dalam konteks UMKM di industri kreatif, dua dimensi entrepreneurial marketing yaitu customer intensity dan value creation memiliki peran penting pada kesuksesan bisnis. Sedangkan, dimensi entrepreneurial marketing lainnya yang mencakup proactiveness, opportunity-focused, risk-taking orientation, innovation-oriented, dan resource leveraging ditemukan tidak mempengaruhi kesuksesan bisnis UMKM di industri ekonomi kreatif. Penelitian ini juga membuktikan bahwa usia perusahaan memoderasi pengaruh customer intensity terhadap kesuksesan bisnis UMKM, namun tidak memoderasi pengaruh value creation terhadap kesuksesan bisnis UMKM.
\end{abstract}

Kata Kunci : entrepreneurial marketing, kesuksesan bisnis, UMKM, usia perusahaan, industri ekonomi kreatif.

${ }^{*}$ E-mail : ari.setiyaningrum@atmajaya.ac.id

Received : 05-03-2020, Accepted : 24-08-2020, Published : 28-08-2020.

P-ISSN : 2087-9954, E-ISSN : 2550-0066. DOI : http://dx.doi.org/10.26418/jebik.v9i2.39818 


\section{PENDAHULUAN}

Industri ekonomi kreatif merupakan industri yang mengalami pertumbuhan cepat di Indonesia. Industri kreatif saat ini menjadi salah satu industri penyumbang paling besar pada Produk Domestik Bruto (PDB) Indonesia. Sumbangan ekonomi kreatif terhadap PDB dari waktu ke waktu terus meningkat yang awalnya sebesar Rp. 952 triliun di tahun 2017, Rp. 1.105 triliun di tahun 2018 dan kemudian meningkat menjadi Rp. 1.200 triliun di tahun 2019 (Dwijayanto, 2019). Penyerapan tenaga kerja di industri ekonomi kreatif juga meningkat yaitu 17,4 persen di tahun 2017 menjadi 18,2 persen di tahun 2018 (Lingga, 2019). Pelaku UMKM di industri ekonomi kreatif perlu mengadopsi entrepreneurial marketing agar mampu bertahan dalam menghadapi kompetisi dengan perusahaan besar dan perubahan lingkungan bisnis mengingat peran penting industri ekonomi kreatif terhadap peningkatan PDB dan penyerapan tenaga kerja.

Entrepreneurial marketing mengacu pada proses pemasaran dengan mana perusahaan berupaya untuk menangkap peluang-peluang yang ada di pasar dengan ketidakpastian tinggi dan dalam situasi dimana perusahaan memiliki sumberdaya yang terbatas (Becherer, Helms \& McDonald, 2012). Konsep mengenai entrepreneurial marketing terus mengalami perkembangan sejalan dengan adanya peningkatan kebutuhan studi yang mengkaitkan konsep entrepreneurship dan pemasaran yang bertujuan untuk meningkatkan kemampuan entrepreneur dalam menjalankan dan mengembangkan bisnis serta menghadapi ancaman lingkungan yang tidak pasti (Setiyaningrum, Udaya \& Efendi, 2015). Entrepreneurial marketing memiliki sejumlah dimensi yang mencakup proactiveness, opportunity-focused, risk-taking orientation, innovation-oriented, customer intensity, resource leveraging, dan value creation (M. H. Schindehutte \& LaForge, 2002).

Studi tentang entrepreneurial marketing banyak menarik perhatian peneliti. Umumnya studi entrepreneurial marketing dilakukan pada konteks perusahaan berskala besar dan penerapannya jauh berbeda dengan perusahaan skala menengah dan kecil (Franco, Santos, Ramalho \& Nunes, 2014). Dalam konteks perusahaan menengah dan kecil, entrepreneurial marketing memainkan peran sangat penting bagi kesuksesan dan keberlanjutan perusahaan karena dengan keterbatasan sumberdaya yang dimiliki, perusahaan menengah dan kecil masih harus berkompetisi dengan perusahaan besar di tengah kondisi lingkungan bisnis yang tidak pasti dan terus berubah. Karena itu, entrepreneurial marketing dinilai lebih cocok diterapkan pada perusahaan menengah dan kecil dibandingkan dengan perusahaan besar (Jones \& Rowley, 2011).

Sejumlah studi mengenai entrepreneurial marketing menemukan bahwa entrepreneurial marketing memiliki peran penting bagi peningkatan kinerja dan kesuksesan binis pada perusahaan skala menengah dan kecil (Becherer et al., 2012; Dzogbenuku \& Keelson, 2019; Fard \& Amiri, 2018; Hacioglu, Eren, Eren \& Celikkan, 2012; Herman, Setiyaningrum \& Ferdinand, 2018; Hoque, Awang \& Gwadabe, 2019; Hoque \& Awang, 2019; Mugambi \& Karugu, 2017; Rodriguez, Gomez \& Ortiz, 2019). Selain itu, entrepreneurial marketing ditemukan dapat meningkatkan pangsa pasar pada perusahaan kecil (Becherer \& Helms, 2016).

Studi terdahulu yang secara spesifik meneliti pengaruh dimensi-dimensi entrepreneurial marketing terhadap kinerja dan kesuksesan bisnis pada konteks perusahaan menengah dan kecil menemukan hasil yang berbeda dan masih belum konklusif. Becherer, Helms \& McDonald (2012) menemukan bahwa dari tujuh dimensi entrepreneurial marketing, enam dimensi yaitu proactiveness, value creation, innovative-oriented, resource leverage, risk-taking orientation, 
dan customer intensity berpengaruh positif terhadap kesuksesan bisnis dan satu dimensi yaitu opportunity-focused tidak berpengaruh terhadap kesuksesan bisnis. Hamali (2015) menemukan bahwa dari tujuh dimensi entrepreneurial marketing, empat dimensi yaitu dimensi proactiveness, resources leveraging, value creation dan customer intensity berpengaruh positif terhadap kinerja bisnis, sedangkan tiga dimensi lainnya yaitu risk-taking orientation, innovativeness, opportunityfocus, dan legitimacy tidak berpengaruh terhadap kinerja bisnis. Olannye \& Edward (2016) menemukan bahwa dimensi proactiveness, innovation, dan opportunity recognition berpengaruh positif terhadap kinerja bisnis. Rashad (2018) menemukan bahwa opportunity focused, calculated risk taken, dan value creation terbukti mempengaruhi kinerja bisnis pada perusahaan kecil, sedangkan proactiveness, innovativeness, customer intensity, dan resource leveraging tidak berpengaruh terhadap kinerja bisnis. Sadiku-Dushi, Dana \& Ramadani (2019) menemukan bahwa opportunity focus, resource leveraging, dan value creation berpengaruh positif terhadap kinerja bisnis pada perusahaan kecil, sedangkan proactiveness, calculated risk taking, innovativeness, dan customer intensity tidak mempengaruhi kinerja bisnis.

Entrepreneurial marketing berperan penting bagi kesuksesan dan keberlanjutan bisnis kecil dalam jangka panjang tanpa terkecuali pada bisnis skala menengah dan kecil di Indonesia. Pada konteks bisnis skala menengah dan kecil khususnya di Indonesia, entrepreneurial marketing masih belum banyak diteliti lebih lanjut terkait dengan dampaknya pada kesuksesan bisnis UMKM yang pada akhirnya dapat mendorong peningkatkan kinerja perekonomian negara di Indonesia. Usia perusahaan pada konteks perusahaan skala menengah dan kecil diidentifikasi sebagai faktor yang dapat memoderasi pengaruh dimensi-dimensi entrepreneurial marketing terhadap kesuksesan perusahaan. Ada tiga alasan yang mendasari mengapa usia perusahaan dapat memperkuat atau memperlemah pengaruh dimensi-dimensi entrepreneurial marketing terhadap kesuksesan perusahaan (Valtakoski \& Witell, 2018). Pertama, dari sisi relasi yang dibangun perusahaan dengan para pelanggan. Perusahaan yang sudah lama beroperasi cenderung memiliki relasi sangat kuat dan intens dengan para pelanggannya sehingga dapat dengan mudah meningkatkan kinerja bisnis misalnya dengan cara membujuk pelanggan yang sudah ada agar bersedia untuk membeli produk-produk lain yang ditawarkan perusahaan, sedangkan bagi perusahaan yang baru beroperasi masih berupaya membangun relasi dengan para pelanggannya dan banyak mengalami kesulitan dalam membujuk pelanggan untuk bersedia membeli produk (Oliva \& Kallenberg, 2003). Kedua, dari sisi karakteristik pelanggan, pelanggan lebih banyak memiliki informasi mengenai produk yang ditawarkan oleh perusahaan yang sudah lama beroperasi daripada perusahaan yang baru beroperasi sehingga perusahaan yang sudah lama beroperasi akan jauh lebih mudah meningkatkan kinerja bisnisnya daripada perusahaan yang baru beroperasi (Raddats, Zolkiewski, Story, Burton, Baines \& Ziaee, 2017). Ketiga, terkait dengan faktor pembelajaran dan pengalaman dalam pengelolaan bisnis, perusahaan yang sudah lama beroperasi lebih banyak memiliki pembelajaran dan pengalaman mengelola bisnis sehingga mampu mengelola bisnis secara lebih efektif dan efisien dibandingkan perusahaan yang baru beroperasi (Jensen \& Szulanski, 2007).

Sejauh ini masih sedikit penelitian yang mengekplorasi lebih jauh mengenai peran dimensi-dimensi entrepreneurial marketing pada kesuksesan bisnis dalam konteks perusahaan menengah dan kecil yang menggunakan obyek penelitian perusahaan mikro, kecil, dan menengah (UMKM) di industri ekonomi kreatif di Indonesia. Disamping itu, hingga saat ini juga belum ada penelitian mengenai entrepreneurial marketing yang dilakukan di Indonesia dengan 
mempertimbangkan aspek usia perusahaan sebagai faktor yang diidentifikasi dapat memoderasi pengaruh dimensi-dimensi entrepreneurial marketing terhadap kesuksesan bisnis UMKM. Usia perusahaan mengacu pada lamanya waktu perusahaan beroperasi. Perusahaan yang belum lama beroperasi dengan perusahaan yang sudah lama beroperasi tentunya memiliki perbedaan dalam menerapkan entrepreneurial marketing dalam kaitannya dengan aspek tahapan perkembangan bisnis, pemahaman serta pengalaman entrepreneur atau pemilik bisnis dalam mengelola bisnis, dan kondisi lingkungan bisnis (Kilenthong, Hills, Hultman \& Sclove, 2010). Karena itu, tujuan dan kontribusi dari penelitian ini adalah melengkapi penelitian terdahulu mengenai pengaruh dimensi-dimensi entrepreneurial marketing yang mencakup proactiveness, opportunity-focused, risk-taking orientation, innovation-oriented, customer intensity, resource leveraging, dan value creation pada kesuksesan bisnis UMKM di industri kreatif di Indonesia dan menyoroti aspek usia perusahaan sebagai variabel moderasi yang dapat memperkuat atau memperlemah pengaruh dimensi-dimensi entrepreneurial marketing pada kesuksesan bisnis.

\section{KAJIAN LITERATUR}

\subsection{Entrepreneurial Marketing}

Entrepreneurial marketing merupakan proses pemasaran dengan mana perusahaan berupaya untuk menangkap peluang-peluang yang ada di pasar dengan ketidakpastian tinggi dan dalam situasi dimana perusahaan memiliki sumberdaya yang terbatas (Becherer et al., 2012). Entrepreneurial marketing berkaitan dengan cara perusahaan untuk memperoleh keunggulan kompetitif di pasar. Morrish (2011) menekankan bahwa entrepreneurial marketing menyoroti pentingnya proses entrepreneurial dalam penciptaan pasar. Dalam konteks ini, entrepreneur mengenali, mengeksplorasi dan mengeksploitasi peluang, mengorganisasi dan mengarahkan strategi operasional dan keputusan strategik yang mempengaruhi dinamika pasar.

Entrepreneurial marketing memiliki peran sangat penting pada perusahaan kecil karena perusahaan kecil menghadapi lebih banyak tantangan ketika harus bersaing dengan perusahaan besar di lingkungan pasar yang tidak pasti. Perusahaan kecil dapat gagal berkompetisi dengan perusahaan besar jika tidak mengadopsi konsep entrepreneurial marketing. Sejumlah studi mengkonfirmasi bahwa entrepreneurial marketing ditemukan sangat efektif ketika perusahaan menghadapi lingkungan yang terus menerus berubah dan memiliki sumberdaya yang terbatas (Becherer \& Maurer, 1997; Chaston, 1997). Entrepreneurial marketing memiliki tujuh dimensi yaitu proactiveness, opportunity-focused, risk-taking orientation, innovation-oriented, customer intensity, resource leveraging, dan value creation (M. H. Schindehutte \& LaForge, 2002).

\subsection{Kesuksesan Bisnis}

Kesuksesan bisnis mengacu pada kemampuan bisnis untuk mencapai tujuan yang ditetapkan (Lucky \& Olusegun, 2012). Kesuksesan bisnis mengindikasikan bahwa bisnis dinilai menguntungkan, efektif, dan efisien. Kesuksesan bisnis dapat diukur dari beberapa aspek, misalnya kesuksesan dalam hal mempertahankan loyalitas pelanggan, kesuksesan dalam hal finansial, dan kesuksesan dalam membangun perusahaan (Becherer et al., 2012). Kesuksesan dalam hal mempertahankan loyalitas pelanggan dapat dilihat dari kepuasan pelanggan pada produk yang ditawarkan perusahaan dan reputasi perusahaan yang positif di mata pelanggan. Kesuksesan dalam hal finansial dapat dilihat dari meningkatnya profitabilitas, meningkatnya 
pendapatan pemilik bisnis, meningkatnya pertumbuhan penjualan, meningkatnya jumlah pelanggan, dan meningkatnya kesejahteraan jangka panjang.

\subsection{Pengaruh Proactiveness terhadap Kesuksesan Bisnis}

Proactiveness mencerminkan kecenderungan pelaku bisnis dalam menunjukkan sifat kepemimpinan dengan cara menginisiasi tindakan-tindakan yang bertujuan untuk mempengaruhi perubahan pada praktek-praktek pemasaran (Fiore, Niehm, Hurst, Son \& Sadachar, 2013). Proactiveness mencakup dua tindakan pemasaran yang saling berhubungan yaitu organizational proactiveness yang menggambarkan tindakan yang dilakukan perusahaan untuk mengantisipasi situasi yang mengancam dan tindakan yang diambil perusahaan untuk mengatasi situasi tersebut. Berdasarkan perspektif entrepreneurial, proactivity menggambarkan tindakan pemasaran dengan mana perusahaan mendefinisikan ulang kondisi eksternal untuk mengurangi ketidakpastian lingkungan dan mengurangi ketergantungan serta kerentanan (Becherer et al., 2012). Proactiveness mengartikan bahwa pemasar tidak memasukkan aspek lingkungan eksternal sebagai situasi dimana perusahaan dapat beradaptasi (Sadiku-Dushi et al., 2019). Studi terdahulu yang dilakukan oleh Becherer et al. (2012) membuktikan bahwa proactiveness berpengaruh positif terhadap kesuksesan bisnis kecil. Temuan tersebut juga diperkuat oleh Hamali (2015) serta Olannye \& Edward (2016) yang menemukan bahwa proactiveness terbukti dapat meningkatkan kinerja bisnis pada perusahaan kecil. Dengan demikian penelitian ini menguji hipotesis:

H1: Proactiveness mempengaruhi kesuksesan bisnis.

\subsection{Pengaruh Opportunity-Focused terhadap Kesuksesan Bisnis}

Opportunity-focused merupakan kecenderungan pelaku bisnis untuk mengidentifikasi kebutuhan pasar yang belum terpenuhi dan mengidentifikasi sumber keunggulan kompetitif (Fiore et al., 2013). Tindakan pemasaran yang penting bagi kesuksesan perusahaan kecil adalah kemampuan perusahaan dalam menggunakan sumberdaya dan kapabilitas yang dimilikinya untuk mengenali serta menangkap peluang-peluang yang ada. Hills, Hultman, Kraus \& Schulte (2010) mengemukakan bahwa opportunity-focused berkaitan dengan identifikasi posisi pasar yang berpotensi dapat menjadi sumber profit yang berkelanjutan bagi perusahaan sehingga pengenalan peluang saat ini memiliki peran sangat penting pada teori dan penelitian mengenai entrepreneurship. Penelitian sebelumnya oleh Rashad (2018) dan Sadiku-Dushi et al. (2019) menemukan bahwa opportunity-focused terbukti dapat meningkatkan kinerja bisnis pada perusahaan kecil. Dengan demikian hipotesis yang diuji dalam penelitian ini adalah:

H2 : Opportunity-focused mempengaruhi kesuksesan bisnis.

\subsection{Pengaruh Risk-taking Orientation terhadap Kesuksesan Bisnis}

Risk-taking orientation merupakan kecenderungan pelaku bisnis untuk menunjukkan pendekatan yang kreatif untuk menurunkan risiko yang melekat melalui tindakan-tindakan baru (Fiore et al., 2013). Pada kerangka kerja entrepreneurial, pengambilan risiko tidak hanya berkaitan dengan kesediaan organisasi untuk mengambil peluang, namun juga berkaitan dengan kemampuan organisasi untuk mengambil tindakan yang dapat menurunkan risiko (Becherer et al., 2012). Dushnitsky (2010) mengkarakteristikkan entrepreneur sebagai individu yang optimis dalam mencapai tujuannya dan tujuan tersebut ditentukan oleh dirinya sendiri, artinya ada entrepreneur yang menilai suatu tindakan sebagai tindakan yang berisiko tinggi dan ada juga 
yang menilainya sebagai tindakan yang tidak terlalu berisiko. Entrepreneur yang pernah sukses dalam merintis bisnis cenderung lebih gigih dan ahli dalam memilih industri yang tepat di saat yang tepat baik untuk memulai bisnis baru ataupun masuk ke pasar umumnya sehingga pada akhirnya dapat mencapai kinerja bisnis yang lebih unggul di industri (Gompers, Kovner, Lemer \& Scharfstein, 2010). Studi sebelumnya oleh Becherer et al. (2012) menunjukkan bahwa risktaking orientation terbukti mempengaruhi kesuksesan bisnis pada perusahaan kecil. Hasil penelitian tersebut diperkuat oleh Rashad (2018) yang juga membuktikan bahwa risk-taking orientation dapat meningkatkan kinerja bisnis pada perusahaan kecil. Berdasarkan hal tersebut peneliti menguji hipotesis:

H3 : Risk-taking orientation mempengaruhi kesuksesan bisnis.

\subsection{Pengaruh Innovation-Oriented terhadap Kesuksesan Bisnis}

Inovasi didefinisikan sebagai kemampuan perusahaan untuk mempertahankan ide-ide baru yang dapat diinterpretasikan menjadi produk, jasa, teknologi, atau pasar baru (Gudda, Bwisa \& Kihoro, 2014). Innovation-oriented merupakan kecenderungan pelaku bisnis mencari ide-ide pemasaran yang baru baik dari dalam perusahaan maupun dari aktivitas eksternal perusahaan (Fiore et al., 2013). Tindakan pemasaran yang berorientasi pada inovasi mendorong perusahaan untuk berfokus pada ide-ide yang mengarah pada penciptaan pasar, produk, atau proses baru (Becherer et al., 2012). Menurut York \& Venkataraman (2010) entrepreneur saat ini ditemukan lebih memperhatikan ketidakpastian lingkungan dan melakukan inovasi sebagai strategi untuk mengatasi adanya ketidakpastian lingkungan. Hasil riset terdahulu yang dilakukan Becherer et al. (2012) membuktikan bahwa innovation-oriented berpengaruh positif terhadap kesuksesan bisnis pada perusahaan kecil. Hasil riset tersebut didukung oleh Rashad (2018) yang juga menemukan bahwa innovation-oriented terbukti mampu meningkatkan kinerja bisnis pada perusahaan kecil. Berdasarkan hal tersebut, hipotesis yang diuji di penelitian ini yaitu:

H4 : Innovation-oriented mempengaruhi kesuksesan bisnis.

\subsection{Pengaruh Customer Intensity terhadap Kesuksesan Bisnis}

Customer intensity merupakan kecenderungan pelaku bisnis untuk menjalin relasi pemasaran yang mengutamakan kebutuhan/ keinginan/ preferensi pelanggan dan berkaitan dengan cara melayani pelanggan dengan cara yang lebih personal (Fiore et al., 2013). Menurut Becherer et al. (2012), dimensi customer intensity seringkali dipandang sebagai kekuatan kendali inti dari pemasaran pada perusahaan yang berorientasi pada pelanggan yang mana perusahaan menggunakan pendekatan inovatif untuk menciptakan, membangun, dan mempertahankan hubungan dengan pelanggan. Customer intensity dipertimbangkan sebagai elemen yang menjadi nilai-nilai inti perusahaan karena mampu membentuk keinginan besar bagi pelanggan dan pemahaman karyawan pada produk atau jasa (Hisrich \& Ramadani, 2018). Studi terdahulu yang dilakukan Becherer et al. (2012) menemukan bahwa customer intensity terbukti berpengaruh positif terhadap kesuksesan bisnis pada perusahaan kecil. Studi tersebut diperkuat oleh Hamali (2015) yang juga membuktikan bahwa customer intensity dapat meningkatkan kinerja bisnis pada perusahaan kecil. Dengan demikian penelitian ini menguji hipotesis:

H5 : Customer intensity mempengaruhi kesuksesan bisnis. 


\subsection{Pengaruh Resource Leveraging terhadap Kesuksesan Bisnis}

Resource leveraging merupakan kecenderungan pelaku bisnis untuk menggunakan sumberdaya yang jumlahnya terbatas secara efektif (Fiore et al., 2013). Resource leveraging tidak hanya terbatas pada bagaimana perusahaan menggunakan sumberdaya yang terbatas secara efektif, namun juga menggunakan proses sinergis yang kreatif. Becherer et al. (2012) mengemukakan bahwa resource leveraging mencerminkan kemampuan perusahaan dalam menggunakan strategi pemasaran yang inovatif untuk dapat mengakses sumberdaya dan melakukan lebih banyak hal dengan sumberdaya yang lebih sedikit. Perusahaan kecil dan menengah ditemukan cenderung lebih suka menggunakan pengungkitan sumberdaya seperti resource sharing dan melakukan outsourcing pada fungsi utama (M. H. Schindehutte \& LaForge, 2002). Riset sebelumnya oleh Becherer et al. (2012) membuktikan bahwa resource leveraging berpengaruh positif terhadap kesuksesan bisnis pada perusahaan kecil. Hasil riset tersebut dikonfirmasi oleh Hamali (2015) dan Sadiku-Dushi et al. (2019) yang juga membuktikan bahwa resource leveraging mampu meningkatkan kinerja bisnis pada perusahaan kecil. Berdasarkan hal tersebut penelitian ini menguji hipotesis:

H6 : Resource leveraging mempengaruhi kesuksesan bisnis.

\subsection{Pengaruh Value Creation terhadap Kesuksesan Bisnis}

Value creation merupakan kecenderungan pelaku bisnis untuk menggunakan usaha dan sumberdaya pemasaran untuk tujuan menemukan dan mengirimkan sumber nilai bagi pelanggan yang belum dimanfaatkan (Fiore et al., 2013). Value creation mengacu pada tugas pemasar untuk dapat menemukan sumber dari nilai pelanggan yang belum digunakan dan menciptakan kombinasi ekslusif dari sumber-sumber tersebut untuk menghasilkan nilai (M. H. Schindehutte \& LaForge, 2002). Penelitian terdahulu yang dilakukan Becherer et al. (2012) menunjukkan bahwa value creation terbukti berpengaruh positif terhadap kesuksesan bisnis pada perusahaan kecil. Temuan penelitian tersebut diperkuat oleh temuan Hamali (2015), Rashad (2018), dan SadikuDushi et al. (2019) yang juga membuktikan bahwa value creation mampu meningkatkan kinerja bisnis pada perusahaan kecil. Berdasarkan hasil temuan penelitian terdahulu, hipotesis yang diuji dalam penelitian ini adalah:

H7: Value creation mempengaruhi kesuksesan bisnis.

\subsection{Usia Perusahaan sebagai pemoderasi pengaruh dimensi-dimensi Entrepreneurial Marketing terhadap Kesuksesan Bisnis}

Penelitian ini dimaksudkan untuk melengkapi penelitian Becherer et al. (2012) dengan menganalisis aspek usia perusahaan sebagai variabel moderasi pada pengaruh dimensi-dimensi entrepreneurial marketing terhadap kesuksesan bisnis. Usia perusahaan menggambarkan lamanya waktu perusahaan menjalankan operasional bisnis. Valtakoski \& Witell (2018) menyatakan ada tiga alasan yang mendasari mengapa perusahaan yang sudah lama beroperasi dan perusahaan yang baru beroperasi akan berbeda dalam hal pencapaian kesuksesan kinerja bisnis. Dari sisi relasi yang dibangun perusahaan dengan pelanggan, perusahaan yang sudah lama beroperasi cenderung memiliki relasi sangat kuat dan intens dengan para pelanggannya sehingga dapat dengan mudah meningkatkan kinerja bisnis dibandingkan dengan perusahaan yang baru beroperasi (Oliva \& Kallenberg, 2003). Dari sisi karakteristik pelanggan, pelanggan lebih banyak memiliki informasi mengenai produk yang ditawarkan oleh perusahaan yang sudah 
lama beroperasi dibandingkan dengan perusahaan yang baru beroperasi (Raddats et al., 2017). Dari sisi pembelajaran dan pengalaman dalam pengelolaan bisnis, perusahaan yang sudah lama beroperasi lebih banyak memiliki pembelajaran dan pengalaman mengelola bisnis sehingga mampu mengelola bisnis secara lebih efektif dan efisien dibandingkan perusahaan yang baru beroperasi (Jensen \& Szulanski, 2007).

Kilenthong et al. (2010) menyatakan bahwa penerapan entrepreneurial marketing pada perusahaan yang sudah lama beroperasi dengan perusahaan yang belum lama beroperasi dapat berbeda terkait dengan usia bisnis dan tahapan siklus bisnis. Karenanya, sejauh mana entrepreneurial marketing berperan penting bagi kesuksesan bisnis dapat ditentukan oleh usia bisnis dan tahapan siklus bisnis. Perusahaan yang baru beroperasi masih berada di tahap awal perkembangan bisnis dan cenderung lebih banyak menghadapi ketidakpastian, ambiguitas, dan turbulensi lingkungan dibandingkan dengan perusahaan yang sudah lama beroperasi. Entrepreneur pada perusahaan yang baru beroperasi kadangkala kurang memiliki pemahaman tentang sifat pasar sehingga menghadapi kesulitan dalam menerapkan strategi pemasaran sehingga perlu lebih banyak fleksibel dan menyesuaikan diri terhadap perubahan lingkungan bisnis.

Perilaku entrepreneurial marketing lebih banyak ditemukan pada perusahaan yang baru beroperasi karena perusahaan tersebut lebih banyak menggunakan riset pemasaran yang kurang formal dan aktivitas mmbangun jejaring terus berkembang seiring usia perusahaan. Penelitian yang dilakukan oleh Kilenthong et al. (2010) membuktikan bahwa terdapat perbedaan penerapan entrepreneurial marketing pada perusahaan yang baru beroperasi dengan perusahaan yang sudah lama beroperasi dalam hal membangun relasi dengan pelanggan. Perusahaan yang baru beroperasi lebih fleksibel dalam membangun relasi dengan pelanggan dan lebih menyesuaikan strategi pemasaran sesuai dengan preferensi pelanggan dibandingkan dengan perusahaan yang sudah lama beroperasi.

Berdasarkan hasil penelitian tersebut dapat disimpulkan bahwa perusahaan yang baru beroperasi dengan perusahaan yang sudah lama beroperasi akan memiliki perbedaan dalam kaitannya dengan perilaku entrepreneur atau pemilik bisnis selaku pihak yang mengelola bisnis sehari-harinya (Kilenthong et al., 2010). Terkait dengan dimensi proactiveness, entrepreneur pada perusahaan yang sudah lama beroperasi akan memiliki pengalaman yang lebih banyak dalam mencari peluang untuk mengantisipasi perubahan lingkungan atau pasar dibandingkan dengan entrepreneur pada perusahaan yang baru beroperasi sehingga usia perusahaan secara potensial dapat memperkuat atau memperlemah pengaruh dimensi proactiveness terhadap kesuksesan bisnis (Kilenthong et al., 2010). Terkait dengan dimensi opportunity-focused, entrepreneur pada perusahaan yang baru beroperasi cenderung akan lebih banyak mencari dan menangkap peluang-peluang baru dibandingkan dengan entrepreneur pada perusahaan yang sudah lama beroperasi sehingga usia perusahaan secara potensial dapat memperkuat atau memperlemah pengaruh dimensi opportunity-focused terhadap kesuksesan bisnis (Kilenthong et al., 2010).

Terkait dengan dimensi risk-taking orientation, entrepreneur pada perusahaan yang baru beroperasi menghadapi risiko yang lebih besar dibandingkan dengan entrepreneur pada perusahaan yang sudah lama beroperasi sehingga usia perusahaan secara potensial dapat memperkuat atau memperlemah pengaruh dimensi risk-taking orientation terhadap kesuksesan bisnis (Kilenthong et al., 2010). Entrepreneur pada perusahaan yang sudah lama beroperasi akan 
memiliki banyak pengalaman dalam hal menghadapi dan mengelola risiko. Terkait dengan dimensi innovation-oriented, entrepreneur pada perusahaan yang sudah lama beroperasi cenderung akan lebih banyak melakukan inovasi agar dapat bertahan di industri dibandingkan dengan entrepreneur pada perusahaan yang baru beroperasi sehingga usia perusahaan secara potensial dapat memperkuat atau memperlemah pengaruh dimensi innovation-oriented terhadap kesuksesan bisnis (Kilenthong et al., 2010).

Terkait dengan dimensi customer intensity, entrepreneur pada perusahaan yang sudah lama beroperasi akan lebih banyak membangun relasi dengan pelanggan untuk tujuan mempertahankan loyalitas pelanggan agar tidak beralih ke pesaing dibandingkan dengan entrepreneur pada perusahaan yang baru beroperasi sehingga usia perusahaan secara potensial dapat memperkuat atau memperlemah pengaruh dimensi customer intensity terhadap kesuksesan bisnis (Kilenthong et al., 2010). Terkait dengan dimensi resource leveraging, entrepreneur pada perusahaan yang sudah lama beroperasi akan lebih banyak melakukan resource sharing dan outsourcing dibandingkan dengan entrepreneur pada perusahaan yang baru beroperasi sehingga usia perusahaan secara potensial dapat memperkuat atau memperlemah pengaruh dimensi resource leveraging terhadap kesuksesan bisnis (Kilenthong et al., 2010). Terkait dengan dimensi value creation, entrepreneur pada perusahaan yang sudah lama beroperasi akan lebih banyak memiliki pengalaman dalam hal menciptakan nilai bagi pelanggan dibandingkan dengan entrepreneur pada perusahaan yang baru beroperasi sehingga usia perusahaan secara potensial dapat memperkuat atau memperlemah pengaruh dimensi value creation terhadap kesuksesan bisnis (Kilenthong et al., 2010). Berdasarkan hal tersebut, hipotesis yang diajukan dalam penelitian ini adalah:

H8 : Usia perusahaan memoderasi pengaruh dimensi-dimensi entrepreneurial marketing (proactiveness, opportunity-focused, risk-taking orientation, innovation-oriented, customer intensity, resource leveraging, dan value creation) terhadap kesuksesan bisnis.

\subsection{Kerangka Penelitian}

Kerangka atau model penelitian dapat dilihat pada Gambar 1.

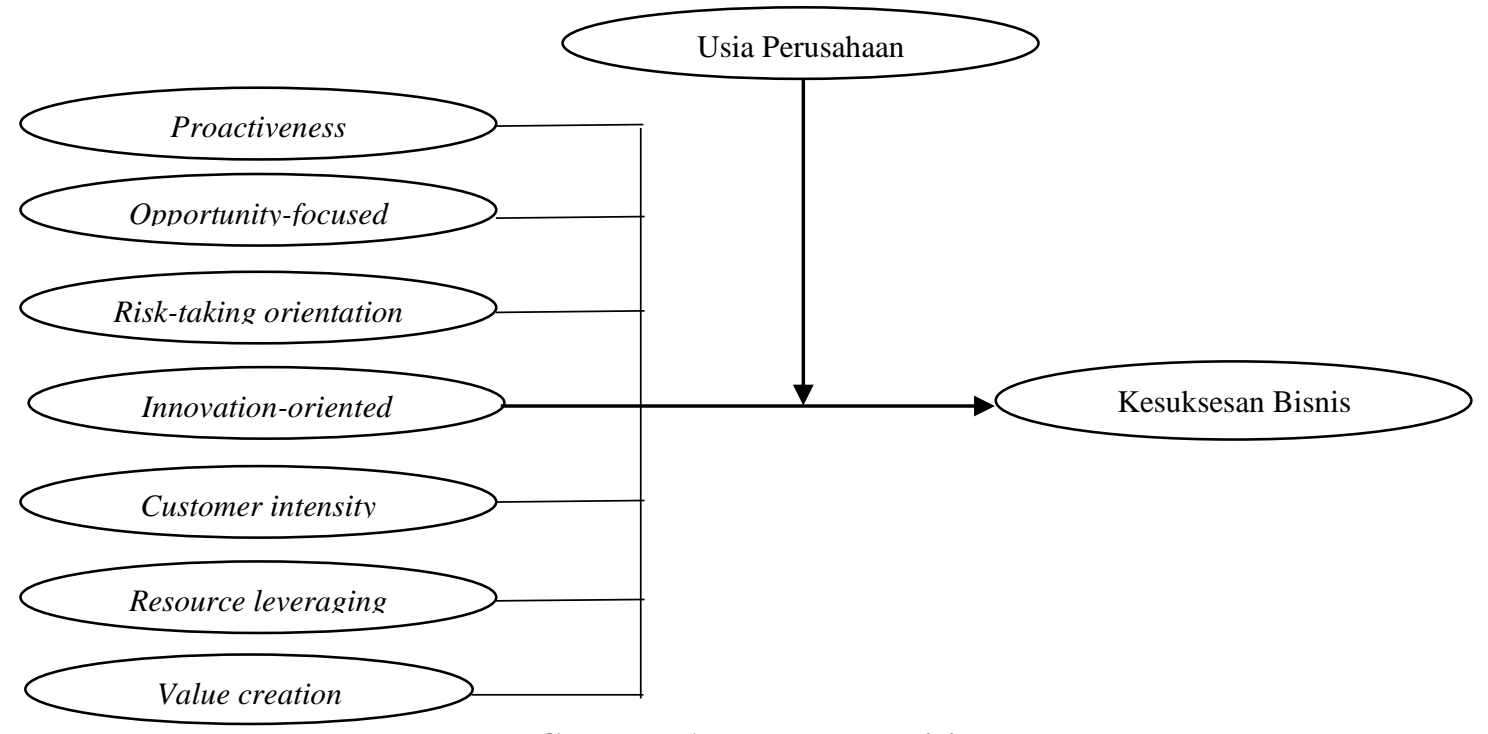

Gambar 1. Model Penelitian 


\section{METODE PENELITIAN}

Penelitian ini merupakan jenis penelitian kuantitatif untuk menguji hipotesis. Data yang digunakan dalam penelitian ini adalah data primer yang dikumpulkan melalui metode survei dengan mendistribusikan kuesioner. Pengumpulan data dilakukan dari bulan Juni hingga Oktober 2019. Populasi dalam penelitian ini yaitu pelaku bisnis UMKM di industri ekonomi kreatif yang berada di Kalimantan. Sampel penelitian yaitu pelaku bisnis UMKM di industri ekonomi kreatif yang berada di Kalimantan Utara. Pertimbangannya adalah Kalimantan Utara secara geografis terletak di wilayah perbatasan negara Indonesia dengan negara tetangga sehingga industri ekonomi kreatif sangat berpotensi untuk lebih dikembangkan dan dapat menjadi pilar ekonomi di wilayah perbatasan (Umacina, 2019). Metode pengambilan sampel adalah nonprobability sampling dengan teknik convenience sampling. Penentuan ukuran sampel menggunakan dasar acuan dari Hair, Black, Babin \& Anderson (2010) yang menyatakan bahwa ukuran sampel adalah lima sampai sepuluh kali jumlah indikator. Indikator di penelitian ini berjumlah 27 buah sehingga ukuran sampel minimal yang harus dipenuhi adalah sebanyak 135 responden. Penelitian ini menggunakan sampel sejumlah 265 pelaku bisnis UMKM di industri ekonomi kreatif dan ukuran sampel ini sudah sesuai dengan ukuran sampel minimal yang direkomendasikan oleh Hair et al. (2010).

Variabel independen dalam penelitian ini yaitu proactiveness, opportunity-focused, risktaking orientation, innovation-oriented, customer intensity, resource leveraging, dan value creation. Variabel dependen yang diteliti adalah kesuksesan bisnis, sedangkan variabel moderasi yang diteliti adalah usia perusahaan. Penelitian ini menggunakan instrumen penelitian yang diadaptasi dari penelitian Becherer et al. (2012). Skala Likert 5 poin dengan rentang nilai mulai dari 1 yang menunjukkan pernyataan Sangat Tidak Setuju (STS) hingga 5 yang menunjukkan pernyataan Sangat Setuju (SS) digunakan untuk mengukur indikator penelitian. Alat analisis data yang digunakan adalah analisis regresi linier berganda dengan software SPSS dan analisis macro process Hayes untuk menguji peran moderasi usia perusahaan pada pengaruh masing-masing dimensi entrepreneurial marketing terhadap kesuksesan bisnis.

\section{HASIL DAN PEMBAHASAN}

\section{Hasil Pretest Instrumen Penelitian}

Sebelum kuesioner didistribusikan ke sampel besar, peneliti melakukan pretest ke 30 responden. Pretest mencakup pengujian validitas dan reliabilitas instrumen penelitian. Hasil pengujian validitas menggunakan korelasi bivariate pearson menunjukkan bahwa seluruh instrumen yang digunakan sudah valid karena seluruh indikator variabel memiliki nilai signifikansi dibawah 0,05 dengan nilai korelasi pearson di atas 0,4. Hasil pengujian reliabilitas menghasilkan nilai cronbach alpha diatas 0,7 untuk seluruh variabel penelitian. Variabel proactiveness menghasilkan nilai cronbach alpha sebesar 0,938; variabel opportunity-focused menghasilkan nilai cronbach alpha sebesar 0,910; variabel risk-taking orientation menghasilkan nilai cronbach alpha sebesar 0,923; variabel innovation-oriented menghasilkan nilai cronbach alpha sebesar 0,891; variabel customer-intensity menghasilkan nilai cronbach alpha sebesar 0,893; variabel resource leveraging menghasilkan nilai cronbach alpha sebesar 0,830 ; variabel value creation menghasilkan nilai cronbach alpha sebesar 0,915; dan variabel kesuksesan bisnis 
menghasilkan nilai cronbach alpha sebesar 0,941. Dengan demikian dapat disimpulkan bahwa instrumen penelitian ini sudah reliabel.

\section{Profil Responden dan Usaha}

Total responden yang berpartisipasi dalam penelitian ini adalah 265 responden yang terdiri atas 40,8\% responden laki-laki dan 59,2\% responden perempuan. Mayoritas responden berusia 24-40 tahun, pendidikan terakhir SMU, dan berstatus sebagai pemilik usaha. Sisi usaha yang dijalankan, mayoritas responden menjalankan usaha dengan cara merintis dari awal, memiliki jumlah karyawan kurang dari 5 orang, produk utama yang ditawarkan adalah produk kuliner dan kerajinan, dan nilai aset usaha diatas Rp. 30 juta.

\section{Hasil Uji Asumsi Klasik Regresi}

Uji asumsi klasik regresi yang digunakan pada penelitian ini mencakup uji normalitas, uji multikolonieritas, dan uji heterosdeskastisitas. Uji autokorelasi tidak digunakan dalam penelitian ini dengan pertimbangan bahwa penelitian ini merupakan penelitian dengan data cross-section. Hasil uji normalitas menggunakan analisis grafik menunjukkan bahwa data yang digunakan dalam penelitian ini telah berdistribusi normal. Hasil uji heteroskedastisitas menggunakan grafik scatterplot menunjukkan bahwa tidak terjadi heteroskedastisitas pada model regresi dalam penelitian ini. Hasil uji multikolinieritas menunjukkan bahwa model regresi dalam penelitian ini menghasilkan nilai tolerance di atas nilai 0,10 dan nilai VIF di bawah nilai 10 untuk seluruh variabel independen yang diteliti sehingga dapat disimpulkan tidak terjadi multikolinieritas pada model regresi.

\section{Hasil Uji Regresi Linier Berganda}

Hasil pengujian regresi linier berganda dapat dilihat pada Tabel 1 dan Tabel 2. Tabel 1 menunjukkan besarnya nilai $R$-square yang dihasilkan adalah 0,729 . Artinya $72,9 \%$ variasi kesuksesan bisnis UMKM dapat dijelaskan oleh ketujuh variabel independen yang diteliti (proactiveness, opportunity-focused, risk-taking orientation, innovation-oriented, customer intensity, resource leveraging, dan value creation) dan sisanya sebesar $27,1 \%$ dijelaskan oleh faktor-faktor lain di luar model penelitian.

Tabel 1. Koefisien Determinasi dan Hasil Uji F

Model Summary

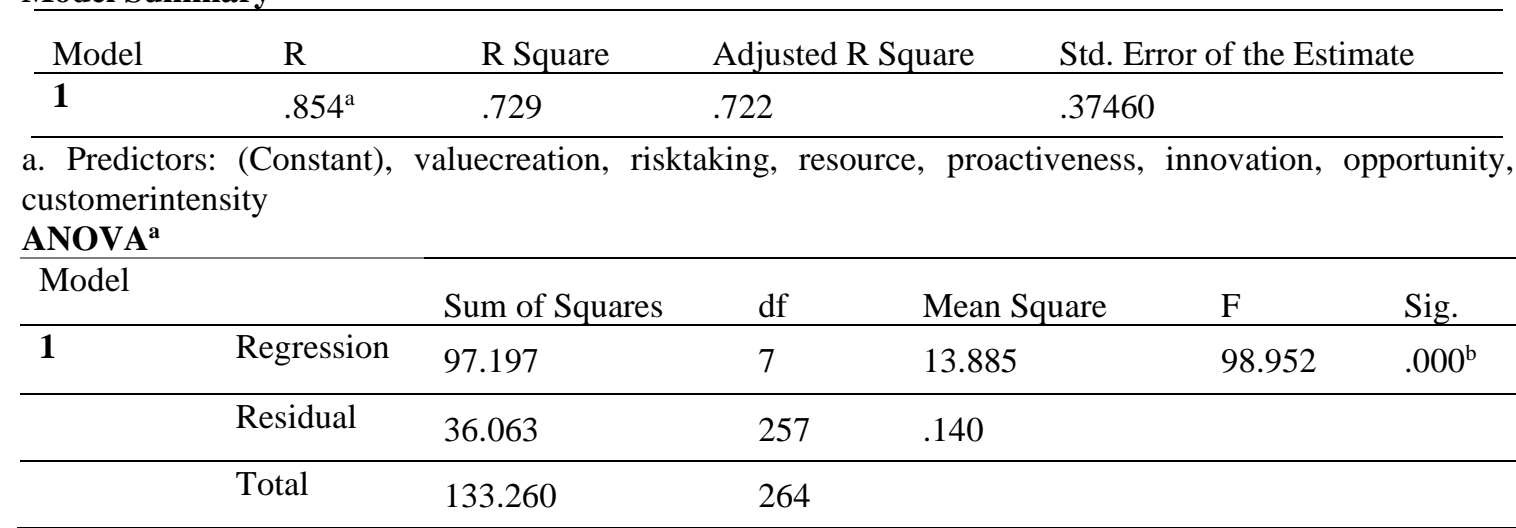

a. Dependent Variable: businesssuccess

b. Predictors: (Constant), valuecreation, risktaking, resource, proactiveness, innovation, opportunity, customerintensity 
Berdasarkan hasil uji $\mathrm{F}$ yang disajikan pada Tabel 1, diperoleh nilai $\mathrm{F}$ hitung sebesar 98,952 dengan tingkat signifikansi 0,000. Karena nilai signifikansi yang dihasilkan di bawah 0,05 maka model regresi dapat digunakan untuk memprediksi kesuksesan bisnis UMKM. Dengan kata lain, proactiveness, opportunity-focused, risk-taking orientation, innovationoriented, customer intensity, resource leveraging, dan value creation secara bersama-sama berpengaruh terhadap kesuksesan bisnis UMKM.

Tabel 2. Hasil Uji t

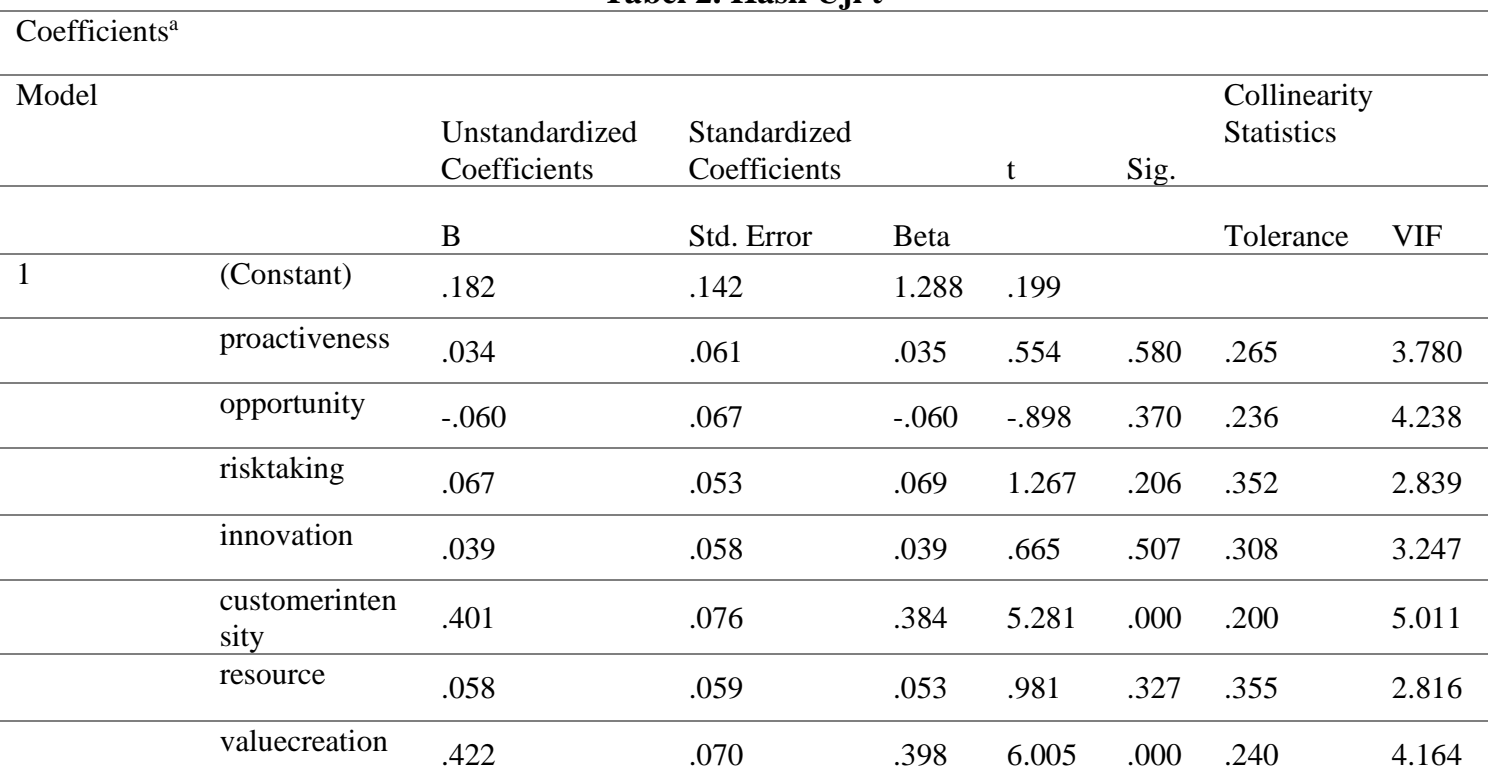

a. Dependent Variable: businesssuccess

Berdasarkan hasil uji t yang disajikan pada Tabel 2 dapat dilihat bahwa dari ketujuh dimensi entrepreneurial marketing yang diteliti, lima dimensi yaitu proactiveness, opportunityfocused, risk-taking orientation, innovation-oriented, dan resource leveraging ditemukan tidak terbukti mempengaruhi kesuksesan bisnis. Dengan demikian H1, H2, H3, H4, dan H6 ditolak. Penelitian ini menemukan bahwa hanya ada dua dimensi entrepreneurial marketing yang berpengaruh terhadap kesuksesan bisnis yaitu customer intensity dan value creation sehingga $\mathrm{H} 5$ dan H7 diterima. Jika dilihat dari nilai beta standardized coefficients yang dihasilkan, value creation ditemukan lebih kuat mempengaruhi kesuksesan bisnis dibandingkan dengan customer intensity. Model persamaan regresi yang dihasilkan adalah:

Kesuksesan bisnis UMKM $=0,182+0,034$ proactiveness $-0,060$ opportunity-focused $+0,067$ risk-taking orientation $+0,039$ innovation-oriented $+0,401$ customer intensity $+0,058$ resource leveraging $+0,422$ value creation $+e$

\section{Hasil Uji Moderasi menggunakan Macro Process SPSS}

Berdasarkan hasil uji regresi berganda ditemukan bahwa customer intensity dan value creation yang berpengaruh terhadap kesuksesan bisnis sehingga untuk analisis moderasi usia perusahaan pada pengaruh dimensi-dimensi entrepreneurial marketing terhadap kesuksesan bisnis hanya dilakukan pada kedua variabel independen tersebut. Hasil uji moderasi menggunakan macro process Hayes dapat dilihat pada Tabel 3 dan Tabel 4. 
Tabel 3. Hasil Uji Moderasi Usia Perusahaan Pada Pengaruh Customer Intensity Terhadap Kesuksesan Bisnis UMKM

\begin{tabular}{|c|c|c|c|c|c|c|}
\hline \multicolumn{7}{|c|}{ Model Summary } \\
\hline $\mathrm{R}$ & R-square & MSE & $\mathrm{F}$ & df1 & df 2 & $\mathrm{p}$ \\
\hline .8246 & .6800 & .1634 & 184.8682 & 3.0000 & 261.0000 & .0000 \\
\hline Model & coeff & se & $\mathrm{t}$ & $\mathrm{p}$ & LLCI & ULCI \\
\hline constant & 3.7522 & .0248 & 151.0946 & .0000 & 3.7033 & 3.8011 \\
\hline customerintensity & .8581 & .0366 & 23.4365 & .0000 & .7860 & .9302 \\
\hline lamaoperasi & -.0418 & .0501 & -.8345 & .4047 & -.1405 & .0568 \\
\hline Int_1 & .1934 & .0737 & 2.6235 & .0092 & .0482 & .3386 \\
\hline \multicolumn{7}{|l|}{ Product terms key: } \\
\hline \multicolumn{7}{|c|}{ Int_1 : customerintensity $\mathrm{x}$ lamaoperasi } \\
\hline \multicolumn{7}{|c|}{ Test(s) of highest order unconditional interaction(s): } \\
\hline \multicolumn{2}{|c|}{ R2-chng } & $\mathrm{F}$ & df1 & df2 & $\mathrm{p}$ & \\
\hline $\mathrm{X} * \mathrm{~W}$ & .0084 & 6.8827 & 1.0000 & 261.0000 & .0092 & \\
\hline
\end{tabular}

Berdasarkan hasil uji moderasi yang ditampilkan pada Tabel 3 ditemukan bahwa usia perusahaan usia perusahaan ditemukan memoderasi pengaruh customer intensity terhadap kesuksesan bisnis. Hal ini ditunjukkan oleh nilai signifikansi yang dihasilkan sebesar 0,0092 dan nilai tersebut berada dibawah 0,05 . Dengan demikian $\mathrm{H} 8$ yang menyatakan usia perusahaan memoderasi pengaruh customer intensity terhadap kesuksesan bisnis diterima.

Tabel 4 menunjukkan bahwa usia perusahaan tidak memoderasi pengaruh value creation terhadap kesuksesan bisnis. Hal ini ditunjukkan oleh nilai signifikansi yang dihasilkan sebesar 0,3492 dan nilai tersebut berada diatas 0,05 . Dengan demikian H8 yang menyatakan usia perusahaan memoderasi pengaruh value creation terhadap kesuksesan bisnis ditolak.

Tabel 4. Hasil Uji Moderasi Usia Perusahaan Pada Pengaruh Value Creation Terhadap Kesuksesan Bisnis UMKM

Model Summary

\begin{tabular}{|c|c|c|c|c|c|c|}
\hline $\mathrm{R}$ & R-square & MSE & $\mathrm{F}$ & df1 & df2 & $\mathrm{p}$ \\
\hline .8192 & .6710 & .1680 & 177.4520 & 3.0000 & 261.0000 & .0000 \\
\hline Model & coeff & se & $\mathrm{t}$ & $\mathrm{p}$ & LLCI & ULCI \\
\hline constant & 3.7522 & .0252 & 148.8999 & .0000 & 3.7026 & 3.8018 \\
\hline valuecreation & .8665 & .0378 & 22.9162 & .0000 & .7920 & .9409 \\
\hline lamaoperasi & -.0732 & .0508 & -1.4386 & .1515 & -.1733 & .0270 \\
\hline Int_1 & .0723 & .0770 & .9379 & .3492 & -.0794 & .2240 \\
\hline \multicolumn{7}{|c|}{ Product terms key: } \\
\hline \multicolumn{7}{|c|}{ Int_1 : valuecreation $\mathrm{x}$ lamaoperasi } \\
\hline \multicolumn{7}{|c|}{ Test(s) of highest order unconditional interaction(s): } \\
\hline & chng & & df1 & df2 & $\mathrm{p}$ & \\
\hline $\mathrm{X} * \mathrm{~W}$ & & 97 & 1.0000 & 261.0000 & .3492 & \\
\hline
\end{tabular}

\section{Pembahasan}

Berdasarkan hasil analisis data, beberapa temuan yang dihasilkan dalam penelitian ini adalah pertama, customer intensity dan value creation berpengaruh positif pada kesuksesan bisnis. Penelitian ini menemukan bahwa dalam konteks UMKM di industri kreatif, kesuksesan bisnis sangat ditentukan oleh customer intensity dan value creation. Dengan kata lain, customer intensity dan value creation menjadi dimensi entrepreneurial marketing yang berperan penting pada kesuksesan bisnis UMKM. Temuan ini mendukung penelitian Becherer et al. (2012) yang menemukan bahwa customer intensity berpengaruh positif terhadap kesuksesan bisnis yang dilihat dari aspek kesuksesan dalam hal mempertahankan loyalitas pelanggan dan value creation 
ditemukan berpengaruh positif terhadap semua aspek kesuksesan bisnis yang mencakup kesuksesan dalam hal mempertahankan loyalitas pelanggan, kesuksesan dalam hal finansial, dan kesuksesan dalam membangun perusahaan. Temuan ini juga mengkonfirmasi penelitian Hamali (2015) yang menemukan bahwa customer intensity dan value creation berpengaruh positif terhadap kesuksesan bisnis. Terkait dengan pengaruh customer intensity terhadap kesuksesan bisnis, temuan ini tidak sejalan dengan penelitian Sadiku-Dushi et al. (2019) yang menemukan bahwa customer intensity tidak terbukti mampu meningkatkan kinerja bisnis pada perusahaan kecil. Namun terkait dengan pengaruh value creation terhadap kesuksesan bisnis, penelitian ini memperkuat temuan Rashad (2018) dan Sadiku-Dushi et al. (2019) yang juga membuktikan bahwa value creation mampu meningkatkan kinerja bisnis pada perusahaan kecil.

Customer intensity mengarah pada upaya perusahaan UMKM untuk menciptakan, membangun, dan mempertahankan hubungan dengan pelanggan dengan cara memberikan perhatian pada apa yang menjadi kebutuhan dan keinginan pelanggan. Upaya untuk memberikan perhatian lebih pada pelanggan menjadi satu faktor kunci yang perlu diperhatikan oleh pelaku UMKM karena sangat menentukan kesuksesan dan kegagalan bisnis. Jumlah pelanggan yang lebih sedikit menuntut perusahaan UMKM untuk dapat melayani pelanggan dengan baik karena jika pelanggan tidak dilayani dengan baik maka pelanggan dapat dengan mudah berpindah ke pesaing yang menawarkan layanan yang lebih baik. Selain itu, kesuksesan dan kegagalan bisnis UMKM juga dipengaruhi oleh value creation. Kemampuan perusahaan untuk menciptakan nilai bagi pelanggan menjadi faktor kunci berikutnya yang menentukan kesuksesan dan kegagalan bisnis kecil. Value creation mengarah pada upaya perusahaan untuk menggunakan usaha dan sumberdaya pemasaran untuk tujuan menemukan, menciptakan, dan mengirimkan sumber nilai yang belum dimanfaatkan bagi pelanggan. Perusahaan UMKM di industri kreatif dituntut memiliki kemampuan untuk menciptakan nilai bagi pelanggan misalnya dengan menawarkan hal-hal yang baru, kreatif, dan unik yang belum dilakukan pesaing untuk mendorong kesuksesan bisnis. Tanpa adanya penciptaan nilai tersebut, perusahaan UMKM tidak akan mampu bersaing.

Kedua, penelitian ini menemukan bahwa dimensi entrepreneurial marketing yang mencakup proactiveness, opportunity-focused, risk-taking orientation, innovation-oriented, dan resource leveraging tidak mempengaruhi kesuksesan bisnis UMKM. Terkait dengan temuan bahwa proactiveness tidak terbukti berpengaruh terhadap kesuksesan bisnis, disatu sisi, temuan ini sejalan dengan temuan Rashad (2018) dan Sadiku-Dushi et al. (2019) yang menemukan bahwa proactiveness tidak berpengaruh terhadap kinerja bisnis perusahaan kecil. Namun disisi lain, temuan penelitian ini bertentangan dengan penelitian sebelumnya yang dilakukan Becherer et al. (2012), Hamali (2015), serta Ollanye \& Edward (2016) yang menemukan bahwa proactiveness terbukti dapat meningkatkan kinerja bisnis pada perusahaan kecil. Terkait dengan temuan bahwa opportunity-focused tidak terbukti berpengaruh terhadap kesuksesan bisnis, disatu sisi, temuan penelitian ini mengkonfirmasi penelitian Becherer et al. (2012) dan Hamali (2015) yang menemukan bahwa opportunity-focused tidak meningkatkan kinerja bisnis pada perusahaan kecil dan disisi lain tidak mendukung penelitian Rashad (2018) dan Sadiku-Dushi et al. (2019) yang menemukan bahwa opportunity-focused berpengaruh positif terhadap kesuksesan bisnis kecil. Terkait dengan temuan bahwa risk-taking tidak terbukti berpengaruh terhadap kesuksesan bisnis, disatu sisi, temuan penelitian ini mengkonfirmasi penelitian Hamali (2015) dan SadikuDushi et al. (2019) yang menemukan hasil bahwa risk-taking orientation tidak terbukti mempengaruhi kesuksesan bisnis pada perusahaan kecil, sedangkan disisi lain temuan penelitian 
ini berbeda dengan penelitian Becherer et al. (2012) dan Rashad (2018) yang berhasil membuktikan bahwa risk-taking orientation berperan penting terhadap kesuksesan bisnis pada perusahaan kecil.

Terkait dengan temuan bahwa innovation-oriented tidak terbukti berpengaruh terhadap kesuksesan bisnis, disatu sisi, temuan ini sejalan dengan temuan Hamali (2015) dan SadikuDushi et al. (2019) yang juga tidak berhasil membuktikan bahwa innovation-oriented dapat meningkatkan kinerja bisnis pada perusahaan kecil. Namun disisi lain, temuan penelitian ini bertentangan dengan penelitian sebelumnya yang dilakukan Becherer et al. (2012) dan Rashad (2018) yang menemukan bahwa innovation-oriented terbukti dapat meningkatkan kinerja bisnis pada perusahaan kecil. Terkait dengan temuan bahwa resource leveraging tidak terbukti berpengaruh terhadap kesuksesan bisnis, disatu sisi, temuan ini sejalan dengan temuan Rashad (2018) yang juga tidak berhasil membuktikan bahwa resource leveraging dapat meningkatkan kinerja bisnis pada perusahaan kecil. Namun disisi lain, temuan penelitian ini tidak sejalan dengan penelitian sebelumnya yang dilakukan Becherer et al. (2012), Hamali (2015), dan Sadiku-Dushi et al. (2019) yang menemukan bahwa resource leveraging terbukti dapat meningkatkan kinerja bisnis pada perusahaan kecil. Penelitian ini menunjukkan bahwa dalam konteks perusahaan UMKM di industri kreatif, kesuksesan bisnis tidak ditentukan oleh proactiveness, opportunity-focused, risk-taking orientation, innovation-oriented, dan resource leveraging. Kemampuan perusahaan untuk proaktif terhadap perubahan lingkungan, berfokus pada pemanfaatan peluang yang ada, berorientasi pada pengambilan resiko, berorientasi pada inovasi, dan mengungkit sumberdaya bukan menjadi faktor utama yang menentukan kesuksesan atau kegagalan bisnis.

Ketiga, terkait dengan peran moderasi usia perusahaan, penelitian ini membuktikan bahwa usia perusahaan ditemukan memoderasi pengaruh customer intensity terhadap kesuksesan bisnis UMKM, namun tidak memoderasi pengaruh value creation terhadap kesuksesan bisnis UMKM. Temuan ini sejalan dengan temuan Kilenthong et al. (2010) yang membuktikan bahwa terdapat perbedaan penerapan entrepreneurial marketing pada perusahaan yang baru beroperasi dengan perusahaan yang sudah lama beroperasi dalam hal intensitas membangun relasi dengan pelanggan. Dalam konteks UMKM di industri kreatif, kemampuan UMKM untuk menciptakan, membangun, dan mempertahankan hubungan dengan pelanggan menjadi semakin besar dampaknya pada kesuksesan bisnis seiring dengan semakin lamanya UMKM beroperasi. UMKM yang sudah lama beroperasi dapat mencapai kesuksesan bisnis yang jauh lebih besar karena memiliki kemampuan yang lebih baik dalam melayani pelanggan seiring dengan lamanya waktu berinteraksi dan menjalin hubungan baik dengan pelanggan. Sedangkan UMKM yang belum lama beroperasi cenderung kurang dapat mencapai kesuksesan bisnis karena belum lama berinteraksi dan menjalin hubungan baik dengan pelanggan.

Terkait dengan usia perusahaan yang tidak memoderasi pengaruh value creation terhadap kesuksesan bisnis, penelitian ini menemukan bahwa dalam konteks UMKM di industri kreatif, kemampuan UMKM untuk menciptakan dan mengirimkan nilai bagi pelanggan memiliki dampak yang sama besarnya pada kesuksesan bisnis antara UMKM yang sudah lama beroperasi dan UMKM yang belum lama beroperasi. Dengan kata lain, semakin lama UMKM beroperasi tidak menjamin bahwa UMKM tersebut semakin memiliki kemampuan untuk menciptakan dan mengirimkan nilai bagi pelanggan yang pada akhirnya mendorong pencapaian kesuksesan bisnis yang lebih besar dibandingkan dengan UMKM yang belum lama beroperasi. Hasil penelitian ini 
tidak mengkonfirmasi pernyataan Valtakoski \& Witell (2018) yang menekankan bahwa ada perbedaan antara perusahaan yang sudah lama beroperasi dan perusahaan yang baru beroperasi dalam hal pengalaman dan pembelajaran selama mengoperasikan bisnis termasuk kemampuan perusahaan dalam menciptakan nilai bagi pelanggan. Temuan ini juga tidak mendukung temuan Kilenthong (2010) yang membuktikan bahwa terdapat perbedaan penerapan entrepreneurial marketing pada perusahaan yang baru beroperasi dengan perusahaan yang sudah lama beroperasi dalam hal penciptaan nilai bagi pelanggan.

\section{SIMPULAN DAN REKOMENDASI}

Penelitian ini menemukan bahwa dalam konteks UMKM di industri kreatif, di satu sisi customer intensity dan value creation memiliki peran penting pada kesuksesan bisnis. Sisi lain, penelitian ini menemukan bahwa proactiveness, opportunity-focused, risk-taking orientation, innovation-oriented, dan resource leveraging tidak mempengaruhi kesuksesan bisnis. Terkait dengan peran moderasi usia perusahaan, hasil penelitian ini membuktikan bahwa usia perusahaan secara signifikan memoderasi pengaruh customer intensity terhadap kesuksesan bisnis, namun tidak memoderasi pengaruh value creation terhadap kesuksesan bisnis.

Penelitian ini memiliki beberapa keterbatasan. Pertama, sampel yang diteliti dalam penelitian ini hanya terbatas pada pelaku UMKM di Kalimantan Utara. Karena itu, rekomendasi bagi penelitian mendatang sebaiknya menggunakan sampel penelitian yang lebih besar cakupannya dan tidak hanya sebatas pada pelaku UMKM di satu tempat tertentu sehingga hasil penelitian dapat lebih digeneralisasikan. Kedua, penelitian ini hanya menguji satu variabel moderasi yaitu usia perusahaan pada pengaruh dimensi-dimensi entrepreneurial marketing terhadap kesuksesan bisnis. Rekomendasi bagi penelitian mendatang adalah mengembangkan lagi model penelitian dengan mempertimbangkan untuk menguji variabel moderasi lainnya seperti karakteristik entrepreneur seperti rekomendasi Kilenthong et al. (2010) yang dapat memoderasi pengaruh dimensi-dimensi entrepreneurial marketing terhadap kesuksesan bisnis.

\section{UCAPAN TERIMA KASIH}

Penulis mengucapkan terima kasih kepada seluruh responden yang telah berpartisipasi dalam penelitian ini dan kepada Fakultas Ekonomi dan Bisnis Unika Atma Jaya yang telah mendanai penelitian ini.

\section{DAFTAR PUSTAKA}

Becherer, R. C., \& Helms, M. M. (2016). The role of entrepreneurial marketing in improving market share for small businesses facing external environmental or resource challenges. Journal of Business and Entrepreneurship, 27(2), 119-147.

Becherer, R. C., Helms, M. M., \& McDonald, J. P. (2012). The effect of entrepreneurial marketing on outcome goals in SMEs. New England Journal of Entrepreneurship, 15(1), $7-18$.

Becherer, R. C., \& Maurer, J. G. (1997). The Moderating Effect of Environmental Variables on the Entrepreneurial and Marketing Orientation of Entrepreneur-Led Firms. Entrepreneurship Theory and Practice, 22(1), 47-58. 
Chaston, I. (1997). Small Firm Performance: Assessing the Interaction between Entrepreneurial Style and Organizational Structure. European Journal of Marketing, 31(11/12), 814831.

Dushnitsky, G. (2010). Entrepreneurial Optimism in the Market for Technological Inventions. Organization Science, 21(1), 150-167.

Dwijayanto, A. (2019). Sampai akhir 2019, sumbangan ekonomi kreatif ke PDB capai Rp 1.200 triliun. Http://Amp.Kontan.Co.Id/News/Sampai-Akhir-2019-Sumbangan-EkonomiKreatif-Ke-Pdb-Capai-Rp-1200-Triliun.

Dzogbenuku, R. K., \& Keelson, S. A. (2019). Marketing and entrepreneurial success in emerging markets: the nexus. Asia Pasific Journal of Innovation and Entrepreneurship, 13(2), $168-187$.

Fard, M. H., \& Amiri, N. S. (2018). The effect of entrepreneurial marketing on halal food SMEs performance. Journal of Islamic Marketing, 9(3), 598-620.

Fiore, A. M., Niehm, L. S., Hurst, J. L., Son, J., \& Sadachar, A. (2013). Entrepreneurial Marketing: Scale Validation with Small, Independently-Owned Business. Journal of Marketing Development and Competitiveness, 7(4), 63-86.

Franco, M., Santos, M. d. F., Ramalho, I., \& Nunes, C. (2014). An Exploratory Study of Entrepreneurial Marketing in SMEs: The Role of The Founder-Entrepreneur. Journal of Small Business and Enterprise Development, 21, 265-283.

Gompers, P., Kovner, A., Lemer, J., \& Scharfstein, D. (2010). Performance Persistence in Entrepreneurship. Journal of Financial Economics, 96(1), 18-29.

Gudda, P., Bwisa, H. M., \& Kihoro, J. M. (2014). Effect of clustering on product innovativeness among Small and Medium Enterprises (SMEs) in Kisumucounty, Kenya. International Journal of Marketing and Technology, 4(1), 35-49.

Hacioglu, G., Eren, S. S., Eren, M. S., \& Celikkan, H. (2012). The effect of entrepreneurial marketing on firms' innovative performance in Turkish SMEs. Procedia- Social and Behavioral Science, 58, 871-878.

Hair, J. F. J., Black, W. C., Babin, B. J., \& Anderson, R. E. (2010). Multivariate Data Analysis (7th ed.). New Jersey: Prentice Hall, Inc.

Hamali, S. (2015). The Effect of Entrepreneurial Marketing on Business Performance: Small Garment Industry in Bandung City, Indonesia. Developing Country Studies, 5(1), 24-29.

Herman, L. E., Setiyaningrum, A., \& Ferdinand, A. T. (2018). Techno-entrepreneurial relationship marketing to ignite the SMEs marketing performance in Indonesia. Quality Access to Success, 19(167), 98-106.

Hills, G. E., Hultman, C. M., Kraus, S., \& Schulte, R. (2010). History, theory and evidence of entrepreneurial marketing-an overview. International Journal of Entrepreneurship and Innovation Management, 11(1), 3-18.

Hisrich, R. D., \& Ramadani, V. (2018). Entrepreneurial Marketing: A Practical Managerial Approach. Edward Elgar.

Hoque, A. S. M. M., \& Awang, Z. B. (2019). Does gender difference play moderating role in the relationship between entrepreneurial marketing and Bangladeshi SMEs performance? Accounting, 5, 35-52. 
Hoque, A. S. M. M., Awang, Z. B., \& Gwadabe, U. M. (2019). The Effect of Entrepreneurial Marketing on Bangladeshi SME performance and the Role of Organizational Culture: A Structural Equation Modelling. Journal of Management and Operation Research, 1(16), $1-21$.

Jensen, R. J., \& Szulanski, G. (2007). Template use and the effectiveness of knowledge transfer. Management Science, 53(11), 1716-1730.

Jones, R., \& Rowley, J. (2011). Entrepreneurial Marketing in Small Businesses: A Conceptual Exploration. International Small Business Journal, 29, 25-36.

Kilenthong, P., Hills, G. E., Hultman, C., \& Sclove, S. L. (2010). Entrepreneurial Marketing Practice: Systematic Relationship with Firm Age, Firm Size, and Operator's Status. International Symposium on Marketing \& Entrepreneurship, 1-15.

Lingga, M. A. (2019). Industri Kreatif Punya Kontribusi pada Pertumbuhan Ekonomi Indonesia. Https://Amp.Kompas.Com/Money/Read/2019/08/16/204100026/Industri-Kreatif-PunyaKontribusi-Pada-Pertumbuhan-Ekonomi-Indonesia.

Lucky, E. O.-I., \& Olusegun, A. (2012). Is Small and Medium Enterprise (SME) an Entrepreneurship. International Journal of Academic Research in Business and Social Science, 2(1), 341-352.

M. H. Schindehutte, M. M., \& LaForge, R. W. (2002). Entrepreneurial Marketing:A Construct for Integrating Emerging Entrepreneurship and Marketing Perspectives. Journal of Marketing Theory and Practice, 10(4), 1-19.

Morrish, S. (2011). Entrepreneurial marketing: a strategy for the twenty-first century? Journal of Research in Marketing and Entrepreneurship, 13(2), 110-119.

Mugambi, E. N., \& Karugu, W. N. (2017). Effect of entrepreneurial marketing on performance of real estate enterprises: A case of Optiven Limited in Nairobi, Kenya. International Academic Journal of Innovation, Leadership and Entrepreneurship, 2(1), 26-45.

Olannye, A. P., \& Edward, E. (2016). The Dimension of Entrepreneurial Marketing on the Performance of Fast Food Restaurants in Asaba, Delta State, Nigeria. Journal of Emerging Trends in Economics and Management Sciences (JETEMS), 7(3), 137-146.

Oliva, R., \& Kallenberg, R. (2003). Managing the transition from products to services. International Journal of Service Industry Management, 14(2), 160-172.

Raddats, C., Zolkiewski, J., Story, V. M., Burton, J., Baines, T., \& Ziaee, B. A. (2017). Interactively developed capabilities: evidence from dyadic servitization relationships. International Journal of Operations \& Production Management, 37(3), 382-400.

Rashad, N. M. (2018). The Impact of Entrepreneurial Marketing Dimensions on the Organizational Performance within Saudi SMEs. Eurasian Journal of Business and Management, 6(3), 61-71.

Rodriguez, J. C., Gomez, M., \& Ortiz, A. L. (2019). Entrepreneurial marketing and business performance: an econometric analysis of SMEs in the tertiary sector of Mexico. Revista Nicolaita de Estudios Economics, 14(1), 29-48.

Sadiku-Dushi, N., Dana, L.-P., \& Ramadani, V. (2019). Entrepreneurial marketing dimensions and SMEs performance. Journal of Business Research, 100, 86-99.

Setiyaningrum, A., Udaya, J., \& Efendi. (2015). Prinsip-Prinsip Pemasaran Plus Tren Terkini Pemasaran Global, Pemasaran Jasa, Green Marketing, Entrepreneurial Marketing, EMarketing. Yogyakarta: Penerbit Andi. 
Umacina, M. D. (2019). Ekonomi Kreatif Bisa Jadi Alternatif: Perbatasan Harus Tampil Beda dan Otentik. Https://Korankaltara.Com/Ekonomi-Kreatif-Bisa-Jadi-AlternatifPerbatasan-Harus-Tampil-Beda-Dan-Otentik/.

Valtakoski, A., \& Witell, L. (2018). Service capabilities and servitized SME performance: Contingency on firm age. International Journal of Operations \& Production Management, 38(4), 1144-1164.

York, J. G., \& Venkataraman, S. (2010). The Entrepreneur-Environment Nexus: Uncertainty, Innovation, and Allocation. Journal of Business Venturing, 25(5), 449-458. 